\title{
UNIVERSITYOF BIRMINGHAM

\section{Towards an integrated system for bio-energy: hydrogen production by Escherichia coli and use of palladium-coated waste cells for electricity generation in a fuel cell.

\author{
Orozco, Rafael; Redwood, Mark; Yong, P; Caldelari, I; Sargent, F; Macaskie, Lynne
}

DOI:

10.1007/s10529-010-0383-9

Citation for published version (Harvard):

Orozco, R, Redwood, M, Yong, P, Caldelari, I, Sargent, F \& Macaskie, L 2010, 'Towards an integrated system for bio-energy: hydrogen production by Escherichia coli and use of palladium-coated waste cells for electricity generation in a fuel cell.', Biotechnology Letters. https://doi.org/10.1007/s10529-010-0383-9

Link to publication on Research at Birmingham portal

\footnotetext{
General rights

Unless a licence is specified above, all rights (including copyright and moral rights) in this document are retained by the authors and/or the copyright holders. The express permission of the copyright holder must be obtained for any use of this material other than for purposes permitted by law.

- Users may freely distribute the URL that is used to identify this publication.

- Users may download and/or print one copy of the publication from the University of Birmingham research portal for the purpose of private study or non-commercial research.

- User may use extracts from the document in line with the concept of 'fair dealing' under the Copyright, Designs and Patents Act 1988 (?)

- Users may not further distribute the material nor use it for the purposes of commercial gain.

Where a licence is displayed above, please note the terms and conditions of the licence govern your use of this document.

When citing, please reference the published version.

Take down policy

While the University of Birmingham exercises care and attention in making items available there are rare occasions when an item has been uploaded in error or has been deemed to be commercially or otherwise sensitive.

If you believe that this is the case for this document, please contact UBIRA@lists.bham.ac.uk providing details and we will remove access to the work immediately and investigate.
} 


\title{
Towards an integrated system for bio-energy: Hydrogen production by Escherichia coli and use of palladium-coated waste cells for electricity generation in a fuel cell
}

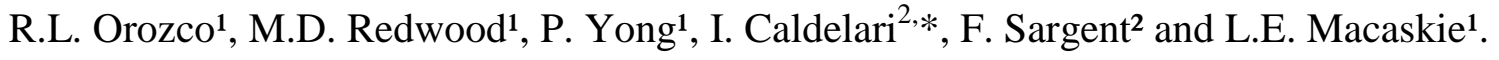 \\ ${ }^{1}$ Unit of Functional Bionanomaterials, School of Biosciences, University of Birmingham, Edgbaston, \\ Birmingham B15 2TT, UK. \\ 2 Division of Molecular Microbiology, College of Life Sciences, University of Dundee, Dundee DD1 \\ 5EH, Scotland. \\ *Present address: Institut de Biologie Moléculaire et Cellulaire, Centre National de la Recherche \\ Scientifique Unité Propre de Recherche, Université Louis Pasteur, 67084 Strasbourg Cedex, France
}

\begin{abstract}
Escherichia coli strains MC4100 (parent) and a mutant strain derived from this (IC007) were evaluated for their ability to produce hydrogen and organic acids (OAs) via fermentation. Following growth, each strain was coated with $\mathrm{Pd}(0)$ via bioreduction of $\mathrm{Pd}(\mathrm{II})$. Dried, sintered Pd-biomaterials ('Bio-Pd') were tested as anodes in a proton exchange membrane (PEM) fuel cell for their ability to generate electricity from hydrogen. Both strains produced hydrogen and OAs but 'palladized' cells of strain IC007 (Bio$\left.\mathrm{Pd}_{\mathrm{IC007}}\right)$ produced $~ 3$-fold more power as compared to Bio-PdMC4100 (56 and $18 \mathrm{~mW}$ respectively). The power output using, for comparison, commercial $\mathrm{Pd}(0)$ powder and Bio-Pd made from Desulfovibrio desulfuricans, was $\sim 100 \mathrm{~mW}$. The implications of these findings for an integrated energy generating process are discussed.
\end{abstract}

Key words: biohydrogen, Escherichia coli, fuel cell, palladium

\section{Introduction}

Hydrogen and fuel cell technologies offer a feasible alternative to fossil fuels that is consistent with environmental demands for low carbon energy and zero emissions. Hydrogen is currently produced mainly as a by-product from the petrochemical industry. This is unsustainable and, furthermore, commercial $\mathrm{H}_{2}$ contains traces of $\mathrm{CO}$, a fuel cell catalyst poison. Currently the life time of a proton exchange membrane fuel cell (PEMFC) is less than 4,000 $\mathrm{h}(\sim 167$ days) whereas that required for a commercial market launch is 40,000 h (5 years; Aki et al. 2005). Photovoltaically-driven water electrolysis produces clean $\mathrm{H}_{2}$ but the requirement for solar energy, the large light capture area, and efficiency of photovoltaic materials are currently limiting factors (MacKay 2008). Use of $\mathrm{H}_{2}$ as a storable energy vector can overcome the problems of intermittency of renewable power systems.

Clean $\mathrm{H}_{2}$ can also be made via microbial fermentation of organic wastes (Davila-Vazquez et al. 2008; Redwood et al. 2009). Biomass (sugary, starchy, and ligno-cellulosic wastes) is an abundant renewable resource and is, therefore, potentially capable of supporting a future sustainable $\mathrm{H}_{2}$ economy. The proportion of the energy demand which could be satisfied in this way is difficult to

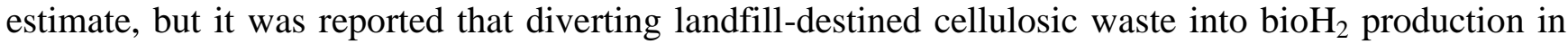
the Netherlands would produce enough $\mathrm{H}_{2}$ to meet $9 \%$ of the domestic energy demand (de Vrije and Claassen 2003). Furthermore it has been predicted that bioconversion of organic waste to biogas could provide up to $7.5 \%$ of the UK's 2020 renewable energy commitment (Anon 2009).

Escherichia coli, an example of a facultative anaerobe, converts sugar via the mixed acid fermentation to gaseous products $\left(\mathrm{H}_{2}\right.$ and $\left.\mathrm{CO}_{2}\right)$ and soluble products including the organic acids (OAs) acetate, lactate, formate and small amounts of succinate, and also ethanol (Clark 1989). $\mathrm{H}_{2}$ production 
in E. coli is mediated by the formate hydrogenlyase (FHL) complex which is located on the inner cell membrane. FHL catalyses the release of $\mathrm{H}_{2}$ and $\mathrm{CO}_{2}$ from formate in response to an increase in intracellular formate, which signals the reduction in extracellular $\mathrm{pH}$ caused by OA formation (Penfold etal. 2003; Redwood 2007; Redwood et al. 2009). The bioH $\mathrm{H}_{2}$ is sufficiently clean (after $\mathrm{CO}_{2}$ removal) to be used directly in a PEMFC without further purification (Macaskie et al. 2005).

Formate is the sole precursor of $\mathrm{H}_{2}$ in $E$. coli with a maximum yield of $2 \mathrm{~mol}$ of $\mathrm{H}_{2}$ per mol of glucose (Clark, 1989). Although other organisms such as Enterobacter and Clostridium can produce, maximally, $4 \mathrm{~mol} \mathrm{H}_{2} / \mathrm{mol}$ glucose via redox carrier-linked reversible hydrogenases these systems are inhibited even at a very low partial pressure of $\mathrm{H}_{2}$, whereas $E$. coli is unaffected due to the use of an irreversible formate-linked hydrogenase system (FHL). The $\mathrm{H}_{2}$ yield was improved further by utilising the produced OAs in a downstream photobioreactor to make a second $\mathrm{H}_{2}$ stream via nitrogenase activity; effectively here the E. coli fermentation has a dual function in both $\mathrm{H}_{2}$ and $\mathrm{OA}$ production (Redwood 2007; Redwood et al. 2009).

Bio-hydrogen has additional potential due to its compatibility with fuel cells (Macaskie et al. 2005). These utilise precious metal catalyst to split the $\mathrm{H}_{2}$ for electricity production; hence the second target for process improvement is the fuel cell itself since robustness is a major limitation for commercial development (Aki et al. 2005; above). Previous work showed that spent yeast biomass, coated with platinum nanoparticles can function as the anode material in a proton exchange membrane fuel Cell (PEMFC) (Dimitriadis et al. 2007) while a parallel study showed that $D$. desulfuricans could behave similarly when coated with either $\operatorname{Pd}(0)$ or $\operatorname{Pt}(0)$ nanoparticles fabricated via the hydrogenase-mediated reduction of $\mathrm{Pd}(\mathrm{II})$ or $\mathrm{Pt}(\mathrm{IV})$ (Yong et al. 2007). The PEMFC power output was comparable to commercial $\mathrm{Pt}(0)$ fuel cell catalyst under similar conditions (Yong et al. 2007). Cells of E. coli can fulfil a similar role but the power output using Bio-Pd $\mathrm{Pd}_{E}$ coli was substantially lower than that obtained by using Bio- $\mathrm{Pd}_{D \text {. desulfuricans }}$ (Yong et al. 2008). For economy and sustainability via re-use of the $\mathrm{H}_{2}-$ producing biomass to make Bio-Pd/Pt and hence electricity 'in process', the power output from a PEMFC made with Bio-Pd $\mathrm{P}_{\text {E. coli }}$ must be increased, but without detriment to the production of either bioH $_{2}$ in the 'dark' fermentation or the organic acid co-products which provide the feedstock for the secondary-stage photofermentation to generate the second $\mathrm{H}_{2}$ stream (Redwood 2008; Redwood et al. 2009). Hence, the dual objectives of this work were to compare hydrogen production and the 'catalytic quality' of Bio-Pd made from cells of E. coli strain MC4100 and its mutant IC007 developed within this study. The downstream photofermentation described elsewhere (Redwood et al. 2009) utilises Rhodobacter sphaeroides to make additional $\mathrm{H}_{2}$ via rapid separation and utilisation of the organic acid products of the $E$. coli fermentation. Therefore, the opportunity was also taken to evaluate the potential to use Bio-Pd $\mathrm{P}_{R \text { sphaeroides }}$ in a PEMFC.

\section{Materials and Methods}

\section{Bacterial strains and hydrogen production.}

Desulfovibrio desulfuricans was as described previously (Yong et al. 2007). R. sphaeroides OU001 was grown as described by Redwood (2007). For comparison of E. coli strains, E. coli HD701 (hydrogen overproducer; derived from the parental strain E. coli MC4100 via upregulation of formate hydrogenlyase: Penfold et al. 2003) was also used. E. coli strain IC007 ( $\square$ focA, $\Delta$ focB, $\square$ nirC, $\square$ hycA, $\triangle l d h A, \triangle t a t A B C::$ Apra $^{\mathrm{R}}$ ) was also derived from the parental strain MC4100. Construction of IC007 took advantage of the PCR-targeting approach of Datsenko and Wanner (2000) and the 'Keio Collection' of single, kanamycin resistance-marked E. coli deletion strains (Baba et al. 2006). First, for deletion of focA and $f o c B$, the apramycin resistance cassette and flanking FLP recombinase recognition sequences encoded on plasmid pIJ773 (Gust et al. 2003) were amplified using primers based on the 
FRT recognition sequences together with the $f o c A$ or $f \circ c B$ flanking sequences. In each case the PCRamplified apramycin resistance cassette was transformed into electro-competent E. coli strain BW25113 harbouring plasmid pKD20 and double cross-overs were selected by plating the transformants onto LB plates containing apramycin. Disruption of the targeted gene was confirmed by PCR, and the marked deletions were subsequently transduced using P1 phage into MC4100 using the method of Miller (1992) The apramycin resistance cassette was subsequently 'flipped out' of the marked deletions using the method described by Datsenko and Wanner (2000) to give strains IC00A and ICO0B. Loss of the apramycin-resistance cassette was confirmed by PCR and apramycin sensitivity. Using identical methods, the focA and $f o c B$ mutant alleles were then combined to give a double mutant strain IC001 (as MC4100, $\triangle f o c A, \Delta f o c B$ ), which was used as a base to build additional mutations upon. The nirC gene was deleted first, using identical methods, to yield IC002 (as MC4100, $\Delta f o c A, \Delta f o c B, \Delta$ nirC). Next, the $\triangle h y c A:: \operatorname{Kan}^{\mathrm{R}}$ allele from E. coli strain JW2695 was moved by $\mathrm{P} 1$ transduction into IC002 and flipped out using pCP20 $\left(\mathrm{Amp}^{\mathrm{R}}\right.$ ) to yield strain IC003 (as MC4100, $\Delta$ focA, $\Delta f o c B, \Delta$ nirC, $\Delta h y c A)$. Next, a $\Delta l d h A:: \mathrm{Cam}^{\mathrm{R}}$ allele, which was prepared by PCR, was introduced into IC003 and flipped out resulting in IC005 (as MC4100, $f$ focA, $\Delta f o c B, \Delta n i r C, \Delta h y c A, \Delta l d h A$ ). Finally, a $\triangle t a t A B C::$ Apra $^{\mathrm{R}}$ cassette was prepared by PCR and introduced into IC005 to yield IC007 (as MC4100, $\triangle$ focA,$\triangle$ focB,$\triangle$ nirC, $\triangle h y c A, \triangle l d h A, \triangle \operatorname{tat} A B C::$ Apra $^{\mathrm{R}}$ ). The genotypic identity of strain IC007 is summarised in Table 1.

Stocks of E. coli strains were maintained at $-80{ }^{\circ} \mathrm{C}$ in $75 \%$ glycerol, plated on nutrient agar (Oxoid) and incubated overnight at $30{ }^{\circ} \mathrm{C}$. For experiments, colonies were picked for pre-culture into nutrient broth (Oxoid, $5 \mathrm{~mL}$ ), with sodium formate $(0.5 \% \mathrm{w} / \mathrm{v}) \mathrm{pH} 7$, and shaken $\left(6 \mathrm{~h}, 30{ }^{\circ} \mathrm{C}\right)$. Cells were inoculated $(10 \mu \mathrm{L})$ in two $2 \mathrm{~L}$ Erlenmeyer flasks containing $1 \mathrm{~L}$ of the same medium and shaken for 16 $\mathrm{h}\left(30{ }^{\circ} \mathrm{C}\right)$. Cell pellets, obtained by centrifugation, were washed twice in $100 \mathrm{~mL}$ phosphate buffered saline (PBS: $1.43 \mathrm{~g} \mathrm{Na}_{2} \mathrm{HPO}_{4} 0.2 \mathrm{~g} \mathrm{KH}_{2} \mathrm{PO}_{4}, 0.8 \mathrm{~g} \mathrm{NaCl}, 0.2 \mathrm{~g} \mathrm{KCl} / \mathrm{L}, \mathrm{pH} 7.0$ ) and resuspended in 20 $\mathrm{mL}$ PBS to produce a concentrated inoculum for fermentation containing $\sim 40-46 \mathrm{~g}$ dry weight/L $\left(\mathrm{OD}_{600 \mathrm{~nm}}\right.$ of 1 corresponded to a concentration of $0.48 \mathrm{~g}$ dry weight/L (a previously determined conversion factor).

Fermentations (two conditions, each in duplicate) were performed consisting of a 5 L fermenter (Fermac 200-series, Electrolab UK) with pH, temperature and agitation control, a "scrubber" column containing $2 \mathrm{M} \mathrm{NaOH}$, a $\mathrm{H}_{2}$ collector cylinder full of water and a $\mathrm{N}_{2}$ gas supply. At least $99.5 \%$ of $\mathrm{CO}_{2}$ was trapped in the scrubber solution as verified by GC (Redwood 2007) and $\mathrm{H}_{2}$ was collected and quantified by water displacement in a graduated collector cylinder. All tubes and connectors were previously sterilized with $70 \%$ ethanol.

The fermentation vessels contained $3 \mathrm{~L}$ of fermentation medium (de-ionized water; in each 3 litre batch: $42.60 \mathrm{~g} \mathrm{Na}_{2} \mathrm{SO}_{4}, 10.46 \mathrm{~g} \mathrm{~K}_{2} \mathrm{HPO}_{4}, 0.20 \mathrm{~g} \mathrm{KH}_{2} \mathrm{PO}_{4}, 0.20 \mathrm{~g}\left(\mathrm{NH}_{4}\right)_{2} \mathrm{SO}_{4}$, pH 5.8). All solutions were prepared using de-ionized water and analytical grade reagents. The following supplements were aseptically added to the fermenter just before inoculation: $1 \mathrm{M} \mathrm{MgSO}_{4} \cdot 7 \mathrm{H}_{2} \mathrm{O}(6 \mathrm{~mL}), 2 \mathrm{M}$ glucose $(30$ $\mathrm{mL} ; 20 \mathrm{mM}$ final concentration), trace elements solution $(9 \mathrm{~mL})$ and polyethylene glycol antifoam (PEG; $0.5 \mathrm{~mL}$ ). Trace elements solution comprised (quantities in $\mathrm{g} / \mathrm{L}$ ): $\mathrm{CaCl}_{2} . \mathrm{H}_{2} \mathrm{O}(0.74) ; \mathrm{ZnSO}_{4} .7 \mathrm{H}_{2} \mathrm{O}$ (0.18); $\mathrm{MnSO}_{4} . \mathrm{H}_{2} \mathrm{O}$ (0.10); disodium-EDTA (20.1); $\mathrm{FeCl}_{3} .6 \mathrm{H}_{2} \mathrm{O}$ (16.7); $\mathrm{CuSO}_{4} .5 \mathrm{H}_{2} \mathrm{O}$ (0.10); $\mathrm{CoSO}_{4} .7 \mathrm{H}_{2} \mathrm{O}(0.21)$.

The system was purged with oxygen free nitrogen (OFN), (through a $0.2 \mu \mathrm{m}$ filter) for at least $30 \mathrm{~min}$ before inoculation. $\mathrm{pH}$ was maintained throughout the fermentation at $\mathrm{pH}$ 5.5-5.7 by dosing $2 \mathrm{M} \mathrm{NaOH}$ and $2 \mathrm{M} \mathrm{H}_{2} \mathrm{SO}_{4}$ via an Electrolab Fermac $260 \mathrm{pH}$ controller, at $30{ }^{\circ} \mathrm{C}$ with stirring $(300 \mathrm{rpm})$. To start each experiment the OFN was stopped, nitrogen tubes were depressurized and valves to the gas collector cylinder were opened to allow the system to equilibrate for at least $45 \mathrm{~min}$.

\section{Sampling and analysis}


For glucose, organic acids and ethanol analysis, samples were periodically withdrawn from the culture, filtered $\left(0.2 \mu \mathrm{m}\right.$ supor membrane syringe filter) and stored at $-20^{\circ} \mathrm{C}$ before analysis. Glucose determination was by the colorimetric dinitrosalicylic acid assay (Chaplin 1986). Organic acids were measured by an anion HPLC (Dionex 600-series) as described previously (Redwood \& Macaskie 2006). Ethanol was analysed using a Cecil Adept HPLC system equipped with Resex-RCM column (Phenomenex); RI detector; temperature $75{ }^{\circ} \mathrm{C}$; eluate $\mathrm{H}_{2} \mathrm{O}$; flow rate $0.5 \mathrm{ml} / \mathrm{min}$; 30 min experiment time. Bacterial growth was monitored via the $\mathrm{OD}_{600}$ of withdrawn samples $\left(\mathrm{OD}_{600}: 1 \equiv 0.482 \mathrm{~g} \mathrm{DW} / \mathrm{L}\right.$; Ultrospec 3300 pro). $\mathrm{H}_{2}$ production was monitored and measured by the displacement of water from graduated cylinders with time-lapse photography for continuous monitoring. $\mathrm{CO}_{2}$ was removed into $2 \mathrm{M}$ $\mathrm{NaOH}$ scrubber solution with universal indicator $\mathrm{pH}$ 9-13. Hydrogen in collectors was confirmed using a hydrogen sensor detector. Previous work (Sauter et al. 1992 and DW Penfold, unpublished) showed that $\mathrm{CO}_{2}$ and $\mathrm{H}_{2}$ are the only gases evolved under these conditions. The $\mathrm{H}_{2}$ yield was calculated in

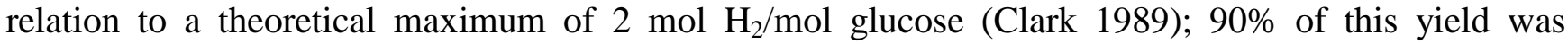
achieved previously under similar conditions (Redwood 2007).

\section{Preparation of fuel cell electrode materials.}

For experiments to test the utility of 'palladised' cells in a fuel cell D. desulfuricans (reference organism: Yong et al. 2007) and E. coli strains (this study) were grown as described by Yong et al. (2002) and Penfold et al. (2006), respectively. Cells were palladised as described previously (5\% Pd by mass; Yong et al, 2007), washed in acetone dried and ground, and then transferred into $10 \mathrm{~mL}$ alumina ceramic crucibles for sintering (i.e. carbonising) in a programmable furnace. The temperature was increased from room temperature to $700{ }^{\circ} \mathrm{C}$ within $4 \mathrm{~h}$ and held at $700{ }^{\circ} \mathrm{C}$ for a further $4 \mathrm{~h}$ before cooling to room temperature in the furnace.

Commercial submicron Pd powder (C-Pd) (Sigma-Aldrich, Germany), and 'Bio-Pds' (20 mg of each, as metal) were mixed separately with pure activated carbon powder ( $80 \mathrm{mg}$; BDH Chemicals Ltd, UK). Nafion ${ }^{\circledR}$ perfluorinated ion-exchange resin $(0.2 \mathrm{~mL} ; 10 \mathrm{wt} \%$ in water, Sigma-Aldrich) and water $(1.0$ $\mathrm{mL}$ ) were added to each sample containing $20 \%$ of $\mathrm{Pd}$ and $80 \%$ of $\mathrm{C}$. The sample was mixed well, manually applied evenly onto $16 \mathrm{~cm}^{2}$ teflon-treated carbon paper (Fuel Cell Scientific, USA), and dried at room temperature. The lab-made electrodes were tested for electricity production versus the commercial Pd powder in a small proton exchange membrane (PEM) fuel cell as described previously (Yong et al. 2007) and the maximum power output (mW) was recorded.

\section{Results and Discussion}

\section{Hydrogen and organic acid production by E. coli strains MC4100 and IC007}

$\mathrm{H}_{2}$ production $(\mathrm{mL})$, biomass $(\mathrm{g})$, glucose consumption (mmol), organic acid (OA) and ethanol production ( $\mathrm{mmol}$ ) were measured and quantified; reproducibility was usually within $10 \%$ between separate experiments. Hydrogen overproduction by E. coli strain HD701 (via derepression of the $\mathrm{H}_{2^{-}}$ producing formate hydrogen lyase complex (Penfold et al. 2003)) and by strains deficient in uptake hydrogenases (Penfold et al. 2006; Redwood et al. 2008) were described previously and production of OA by the latter was also quantified (Redwood \& Macaskie 2006). A combination of the hycA and tat mutations did not increase hydrogen production over that obtained with one mutation alone (Penfold et al. 2006). Hence, in this work, further metabolic engineering of E. coli was performed. A new strain (IC007) was prepared that combined mutations additional to those in the hycA and tatABC genes previously studied (Table 1). Strain IC007 was rendered devoid its formate transporters (FocA and 
FocB), and the FocA/B homolog NirC, in an attempt to impair formate secretion during fermentation and utilise early and sustained formate hydrogenlyase (FHL) activity. In addition, strain IC007 lacks an active $l d h A$ gene, which encodes an NADH-dependent lactate dehydrogenase that is normally active in the later stages of fermentative growth. The rationale in removing LdhA was to prevent the metabolism of pyruvate to lactate and, instead, shunt additional pyruvate towards formate and hence boost $\mathrm{H}_{2}$ production.

The fermentation kinetics of strains MC4100 and IC007 are compared in Figure 1 and summarised in the fermentation balances shown in Table 2. During a $24 \mathrm{~h}$ fermentation, both strains grew very slightly, limited by the low concentration of added nitrogen source; note that prior to the incubation the cells had been grown aerobically to high density, with formate as a FHL inducer (Redwood et al. 2008). The parent strain MC4100 consumed all of the initial added glucose within $24 \mathrm{~h}$, whereas the mutant strain IC007 consumed only $70 \%$ of the added glucose over $24 \mathrm{~h}$. Correspondingly, the MC4100 parent strain evolved $\mathrm{H}_{2}$ more rapidly than strain IC007 (Fig. 1 a,b), the rate peaking at $\sim 4.2 \mathrm{mmol}$ $\mathrm{H}_{2} / \mathrm{h}$ during the initial $10 \mathrm{~h}$ and gradually decreasing within $24 \mathrm{~h}$. The overall yields of $\mathrm{H}_{2}$ produced were $41 \%$ and $37 \%$ for strains MC4100 and IC007, respectively, and not significantly different on the basis of the two experiments reported (Table 2).

Analysis of OA production (Fig $1 \mathrm{c}, \mathrm{d}$ and Table 2) showed that lactate was the main organic product of the parent strain MC4100 but the lactate yield was negligible in strain IC007 due to the ldhA mutation. However, the result of this was not an increase in $\mathrm{H}_{2}$ production but in non-lactate byproducts, especially pyruvate, succinate and ethanol. Despite the loss of lactate production, the overall yield of $\mathrm{H}_{2}$ in strain IC007 was not significantly different from the parent strain MC4100, which can be attributed to the accumulation of alternative byproducts (succinate) and $\mathrm{H}_{2}$ precursors (pyruvate and formate). The inability of strain IC007 to reassimilate all of the formate initially secreted into the reaction medium may be attributed to the lack of dedicated formate transport machinery in this strain and partially accounts for the reduced $\mathrm{H}_{2}$ yield observed. Clearly, lactate dehydrogenase is a major route for pyruvate dissimilation and recycling of NADH during fermentation. The loss of ldhA leads to the accumulation and ultimate secretion of pyruvate; the shortfall in NADH recycling via removal of lactate production is compensated by an increased production of ethanol and succinate.

Similar observations regarding different $l d h$ mutants were made by Mat-Jan et al. (1989) and Zelic et al. (2004) in $l d h$ mutants. However, we also observed that when strain IC700 was allowed to ferment for a further $24 \mathrm{~h}$, the pyruvate was reassimilated, which is in accordance with the observations of Sode et al. (1999) where, likewise, the reaction was followed to completion.

We conclude that eliminating lactate production did not benefit the $\mathrm{H}_{2}$ yield in this study as the additional intermediate either accumulated or gave enhanced production of alternative products, particularly succinate and ethanol. Eliminating succinate production would be difficult due to the key role of succinate-producing enzymes in central metabolism. Further, succinate is potentially useful in the downstream photobioreactor and hence could be re-used 'in process'. Jointly upregulating the activity of pyruvate formate lyase and FHL could hypothetically channel more pyruvate intermediate towards $\mathrm{H}_{2}$ production, an approach to be addressed in future work. Work is currently in progress to reduce the production of ethanol since this product cannot be transferred easily into the downstream photobioreactor but this metabolic engineering will have implications in the ability of the cells to recycle NADH and such mutants may be highly impaired or non-viable.

Electricity production by palladised cells of E. coli in a fuel cell.

Cells of the E. coli strains MC4100 and IC007 (this study), together with strain HD701 (hydrogen production was as described previously: Penfold et al. 2003), R. sphaeroides (Redwood 2007) and $D$. desulfuricans (positive control) were coated with palladium nanoparticles as described previously 
(Yong et al. 2007) and tested for their ability to produce electricity as anodes in a PEM fuel cell. Sintering of palladised biomass was essential to obtain catalytic activity (P. Yong, unpublished) since biomass is predominantly water and sintering carbonises the biomass to make it electrically conductive. As shown in Fig. 2 and Table 3, Bio-Pd ${ }_{D \text {. desulfuricans }}$ produced power comparably to commercial finelyground $\mathrm{Pd}(0)$ while Bio-Pd $\mathrm{MC}_{\mathrm{M} 100}$ and $\mathrm{Bio}-\mathrm{Pd}_{\mathrm{HD} 701}$ produced little power $(\sim 18-28 \mathrm{~mW})$. However Bio$\mathrm{Pd}_{\mathrm{IC} 007}$ produced $\sim 56 \mathrm{~mW}$, which was $\sim$ three-fold higher than the parent strain $(\sim 18 \mathrm{~mW})$ or Bio$\mathrm{Pd}_{\text {R. sphaeroides. }}(\sim 20 \mathrm{~mW})$. Representative data are shown, since the power output is critically dependent on the exact preparation of the electrode but in 3 replicate experiments the $\operatorname{Bio}-\operatorname{Pd}(0)$ of the mutant outperformed that of the parent strain consistently as shown.

From these results it can be concluded that the catalytic activity of the palladium in a fuel cell relates to the enzymatic composition and localisation in the strain which produced it. A similar conclusion with respect to chemical catalysis was drawn (Rousset et al. 2006) using a mutant of D. fructosovorans which lacked its periplasmic hydrogenases; here, the $\operatorname{Pd}(0)$ relocated to the site of the remaining cytoplasmic hydrogenase (Mikheenko et al. 2008) and was catalytically more active in the reduction of $\mathrm{Cr}(\mathrm{VI})$ (Rousset et al. 2006). In the present case the key difference between strains HD701 and IC007 is that the Tat transport system is missing, and therefore there are no functional periplasm-facing hydrogenases. Therefore, strain IC007, like the D. fructosovorans mutant (above) may be location-modified with respect to making Pd-nanoparticles. However no obvious differences were observed in initial comparisons of the Bio-Pd produced by strains MC4100 and IC007 (Yong et al. 2010) and a high resolution TEM study is clearly warranted. Taken together, the two studies using $D$. fructosovorans and E. coli indicate that 'relocating' the Pd-nanoparticles may be beneficial to the 'quality' of the catalyst produced. Potential pleiotropic effects of the mutations introduced into strain IC007 were not investigated but warrant further investigation. The extent to which the 'biochemical' component of the Bio-Pd moderates the catalytic activity of its $\operatorname{Pd}(0)$ 'partner' after sintering of the material is a subject of current investigation.

\section{Conclusion}

In terms of $\mathrm{H}_{2}$ production strain IC007 offers little benefit over a 24 hour period as compared to its parent strain MC4100, although its ability to produce more succinate and pyruvate could be beneficial as secondary products. However, in terms of an integrated energy process, where biomass is re-used 'in process' the mutant strain offers more potential to make a better fuel cell although this still falls short (by $\sim 50 \%$ ) of the use of $D$. desulfuricans as a support for 'Bio-Pd' for this purpose. The extent to which further molecular engineering could improve the rates and yields of hydrogen production without compromising fuel cell catalyst performance is the subject of ongoing studies.

\section{Acknowledgements}

The financial support of the BBSRC (Grant Nos BB/C516195/2 and BB/E003788/1), the EPSRC (Grant Nos EP/D05768X/1 and EP/E034888/1), the Royal Society (Industrial Fellowship to LEM), Advantage West Midlands (Grant ref. POC46) and the Government of Mexico (studentship no. 203186) to RLO is acknowledged, with thanks.

\section{References}

Aki H, Murata A, Yamamoto S, Kondoh J, Maeda T, Yamaguchi H, Ishii, I (2005) Penetration of residential fuel cells and $\mathrm{CO}_{2}$ mitigation - case studies in Japan my multi-objective models. Int $\mathbf{J}$ Hyd Energy, 30: 943-952.

Anon: Department of Food and Rural Affairs (Feb 2009) Anaerobic Digestion - Shared Goals. www.defra.gov.uk Accessed May 2010. 
Baba T, Ara T, Hasegawa T, Takai Y, Okumura Y, Baba M Datsenko KA, Tomita M, Wanner BL, Mori H (2006) Construction of Escherichia coli K-12 in-frame, single-gene knockout mutants: the Keio collection. Mol Syst Biol 2: 0008.

Berks BC, Palmer T \& Sargent F (2003) The Tat protein translocation pathway and its role in microbial physiology. Adv Microbial Physiol 47: 187-254.

Bunch PK, Mat-Jan F, Lee N, Clark DP (1997) The ldhA gene encoding the fermentative lactate dehydrogenase of Escherichia coli. Microbiology 134: 187-195.

Chaplin MF (1986). Monosaccharides. In Carbohydrate analysis: a Practical Approach. Chaplin MF, Kennedy JF, (Eds). IRL Press at Oxford University press, UK: p.3

Clegg FYS, Griffiths L, Cole JA, (2002) The roles of the polytopic membrane proteins NarK, NarU and NirC in E.coli K-12- two nitrate and three nitrite transporters Mol Microbiol 44: 143-155.

Datsenko KA, Wanner BL (2000) One-step inactivation of chromosomal genes in Escherichia coli K12 using PCR products. Proc Natl Acad Sci U S A 97:6640-6645

Davila-Vazquez G, Arriaga S, Alatriste-Mondragon F, de Leon-Rodriguez A, Rosales-Colunga LM, Razo-Flores E (2008) Fermentative biohydrogen production: trends and perspectives. Rev Environ Sci Biotechnol 7:27-45.

de Vrije T, Claassen PAM (2003) Dark hydrogen fermentations. in Bio-methane and Bio-hydrogen. Reith JH, Wijffels RH, Barten H, (Eds). Petten, Netherlands, Dutch Biological Hydrogen Foundation: 103-123.

Dimitriadis S, Nomikou N, McHale Biotechnology AP (2007) Pt-based electro-catalytic materials derived from biosorption processes and their exploitation in fuel cell technology. Biotechnol Lett 29: 545-551.

Gust B, Challis GL, Fowler K, Kieser T, Chater KF (2003) PCR-targeted Streptomyces gene replacement identifies a protein domain needed for biosynthesis of the sesquiterpene soil odor geosmin. Proc Natl Acad Sci 100:1541-1546

Macaskie LE, Baxter-Plant VS, Creamer NJ, Humphries AC, Mikheenko IP, Penfold DW, Yong P (2005) Applications of bacterial hydrogenases in waste decontamination, manufacture of novel bionanocatalysts and in sustainable energy. Biochem Soc Trans 33; 76-79.

MacKay DJC (2008) Sustainable Energy - without the hot air., UIT Cambridge. Published online at www.withouthotair.com. Accessed, June 2010.

Mat-Jan F, Alam KY, Clark DP (1989) Mutants of Escherichia coli deficient in the fermentative lactate dehydrogenase. J Bacteriol 171: 342-348.

Mikheenko I, Rousset M, Dementin S, Macaskie LE (2008) Bioaccumulation of palladium by Desulfovibrio fructosovorans and hydrogenase deficient strains. Appl Environ Microbiol 19: 611446146

Miller JH (1992) A Short Course in Bacterial Genetics: A Laboratory Manual and Handbook for Escherichia coli and Related Bacteria, Cold Spring Harbor Laboratory Press, New York, USA.

Miller M (2005) Twin-arginine specific protein export in Escherichia coli Res Microbiol 156: 131-136

Penfold DW, Forster CF, Macaskie LE (2003) Increased hydrogen production by Escherichia coli strain HD701 in comparison with the wild-type parent strain MC4100. Enz Microbial Technol 33:185-189.

Penfold DW Sargent F, Macaskie LE (2006) Inactivation of the Escherichia coli K-12 twin-arginine translocation system promotes increased hydrogen production FEMS Microbiol Lett 262: 135-137.

Redwood MD (2007) Bio-hydrogen and biomass supported palladium catalyst for energy production and waste minimisation. Ph.D. Thesis, University of Birmingham, UK

Redwood MD, Macaskie LE (2006). A two-stage, two-organism process for biohydrogen from glucose. Int J Hydrogen Energy 31:1514-1521.

Redwood, MD, Mikheenko IP, Sargent F and Macaskie LE. (2008) Dissecting the roles of E. coli hydrogenases in biohydrogen production. FEMS Microbiol Letts 278: 48-55. 
Redwood MD, Paterson-Beedle M, Macaskie LE (2009) Integrating dark and light biohydrogen production strategies: towards the hydrogen economy. Rev Environ Sci Bio/Technol 8:149-185.

Rousset M L, Casalot P, de Philip A, Bélaich I, Mikheenko I, Macaskie LE (2006) Use of bacterium strains for the preparation of metallic biocatalysts, in particular for the preparation of palladium biocatalysts. European Patent Application Number: WO/2006/087334. International Application No.: PCT/EP2006/05094.

Saier MH, Ford S, Garg J, Haggerty DA, Hutchinson WJ, Jack DL, Lai EC, Liu HJ, Nusinew DP, Omar AM, Pao SS, Paulsen IT, Quen JA, Sliwinski M, Tseng TT, Wachi S, Young GB, (1999) Phylogenetic characterization of novel transport protein families revealed by genome analysis. Biochim Biophys Acta 1422: 1-56.

Sauter M, Bohm R, Bock A (1992) Mutational analysis of the operon (hyc) determining hydrogenase-3 formation in Escherichia coli. Mol Microbiol 6:1523-1532.

Sode K, Yamamoto S, and Tomiyama M. (1999) Construction and characterisation of fermentative lactate dehydrogenase E. coli mutant and its potential for bacterial hydrogen production. Appl Biochem Biotechnol 77-79: 317-323.

Suppmann B, Sawers G (1994) Isolation and characterization of hypophosphite resistant mutants of Escherichia coli: identification of the FocA protein, encoded by the pfl operon, as a putative formate transporter. Mol Microbiol 11: 865-982.

Yong P, Rowson NA, Farr JP, Harris IR, Macaskie LE (2002) Bioreduction and bio-crystallization of palladium by Desulfovibrio desulfuricans NCIMB 8307. Biotechnol Bioeng 80:369-379.

Yong P, Paterson-Beedle M, Mikheenko IP, Macaskie LE (2007) From biomineralization to fuel cells: biomanufacture of $\mathrm{Pt}$ and $\mathrm{Pd}$ nanocrystals for fuel cell electrode catalyst. Biotechnol Lett 29:539544.

Yong P, Mikheenko I., Macaskie LE (2008) Manufacturing of fuel cell catalysts by bio-crystallization. J Biotechnol 136S: S374-S375

Zelic B, Gostovic S, Vuorilehto K, Vasic-Racki D, and Takors R (2004) Process strategies to enhance pyruvate production with recombinant Escherichia coli: From repetitive fed-batch to in situ product recovery with fully integrated electrodialysis. Biotechnol Bioeng 85: 638-646 
Table 1 Genotypic identity of strain E. coli IC007

Deletion Affected gene product (resultant phenotype)

$\triangle f o c A \quad$ Formate transporter

(impaired ability to secrete and take up formate)

$\triangle f o c B$

Putative formate transporter

(impaired ability to secrete and take up formate)

$\triangle h y c A$

$\Delta l d h A$

$\triangle \operatorname{tat} A B C$

$\Delta n i r C$
Formate hydrogen lyase (FHL) regulatory protein (upregulated $\mathrm{FHL} ; \mathrm{H}_{2}$ overproduction)

NADH-linked fermentative lactate dehdrogenase

( lactate not produced)

The twin arginine translocation system: transports folded proteins over membranes

(tat inactivation prevents uptake hydrogenase transport; increases $\mathrm{H}_{2}$ production)

Nitrite transporter, paralogous with FocA/B

(impaired ability to secrete and take up formate)
Reference

Suppmann et al. 1994

Saier et al. 1999

Sauter et al. 1992; Penfold et al. 2003

Bunch et al. 1997

Berks et al. 2003; Miller 2005

Penfold et al. 2006

Clegg et al. 2002

Strain IC007 was made from its parent MC4100 as described in Materials and Methods. It combines the ability to overproduce hydrogen via deletion of the FHL regulator FhlA and the Tat system with impaired ability to transport formate. It does not make lactate, potentially increasing the metabolic flux into the other fermentation products. 
Table 2. Fermentation balance of E. coli strains MC4100 and IC007

\begin{tabular}{|c|c|c|c|c|c|c|c|c|c|c|c|c|}
\hline \multirow{2}{*}{ Strain } & \multirow{2}{*}{ Repeat } & \multirow{2}{*}{ Time } & \multicolumn{8}{|c|}{ Product yields (mol/mol glucose)* } & \multirow{2}{*}{$\begin{array}{l}\text { Growth } \\
\text { (g/mol } \\
\text { glucose) }\end{array}$} & \multirow{2}{*}{$\begin{array}{c}\text { Carbon } \\
\text { balance } \\
* * *\end{array}$} \\
\hline & & & $\mathrm{Lac}$ & Pyr & Form & Succ & Ac & $\mathrm{EtOH}$ & $\mathrm{H}_{2}$ & $\mathrm{CO}_{2} * *$ & & \\
\hline \multirow{2}{*}{ MC4100 } & Expt 1 & 22.75 & 0.892 & 0.000 & 0.048 & 0.200 & 0.354 & 0.405 & 0.788 & 0.51 & 3.99 & $99 \%$ \\
\hline & Expt 2 & 22.75 & 0.789 & 0.000 & 0.024 & 0.196 & 0.326 & 0.438 & 0.849 & 0.54 & 4.49 & $93 \%$ \\
\hline \multirow{2}{*}{ IC007 } & Expt 1 & 23.5 & 0.008 & 0.518 & 0.079 & 0.492 & 0.227 & 0.704 & 0.735 & 0.36 & 4.41 & $102 \%$ \\
\hline & Expt 2 & 23.5 & 0.007 & 0.527 & 0.069 & 0.479 & 0.222 & 0.685 & 0.760 & 0.36 & 2.64 & $99 \%$ \\
\hline
\end{tabular}

* Propionate and butyrate were not detected. Lac: lactate; Pyr: pyruvate; Form: formate; Succ: succinate; Ac: acetate; EtOH: ethanol

** The yield of $\mathrm{CO}_{2}$ was estimated as described by Redwood et al (2007), equation 2.

*** Carbon balance was calculated as Redwood et al (2007), but including pyruvate (3 carbon equivalents).

Table 3. Maximum power output $\left(\mathrm{P}_{\max }, \mathrm{mW}\right)$ from a PEM fuel cell using anodes made from commercial precious metals and Bio-Pd..

Preparation

Commercial $\mathrm{Pt}(0)$

Bio- $\mathrm{Pt}_{D .}$ desulfuricans

Commercial $\operatorname{Pd}(0)$

Bio- $\mathrm{Pd}_{D \text {. desulfuricans }}$

Bio-Pd $d_{\text {E. coli } \mathrm{HD} 701}$

Bio-Pd $\mathrm{P}_{\text {. coli } \mathrm{MC} 4100}$

Bio-Pd E. coli IC007

Bio-Pd $\mathrm{P}_{\text {R. sphaeroides OU001 }}{ }^{*}$
$\mathrm{P}_{\text {max }}(\mathrm{mW})$

170

170

100

108

28

18

56

19.5
Reference

Yong et al. 2007

Yong et al. 2007

This study

This study

This study

This study

This study

Redwood 2007

Native metallised biomass was inactive in a PEMFC. Samples (all 5\% Pd w/w) were, therefore, sintered before use to carbonise the biomass, as described in Materials and Methods. 

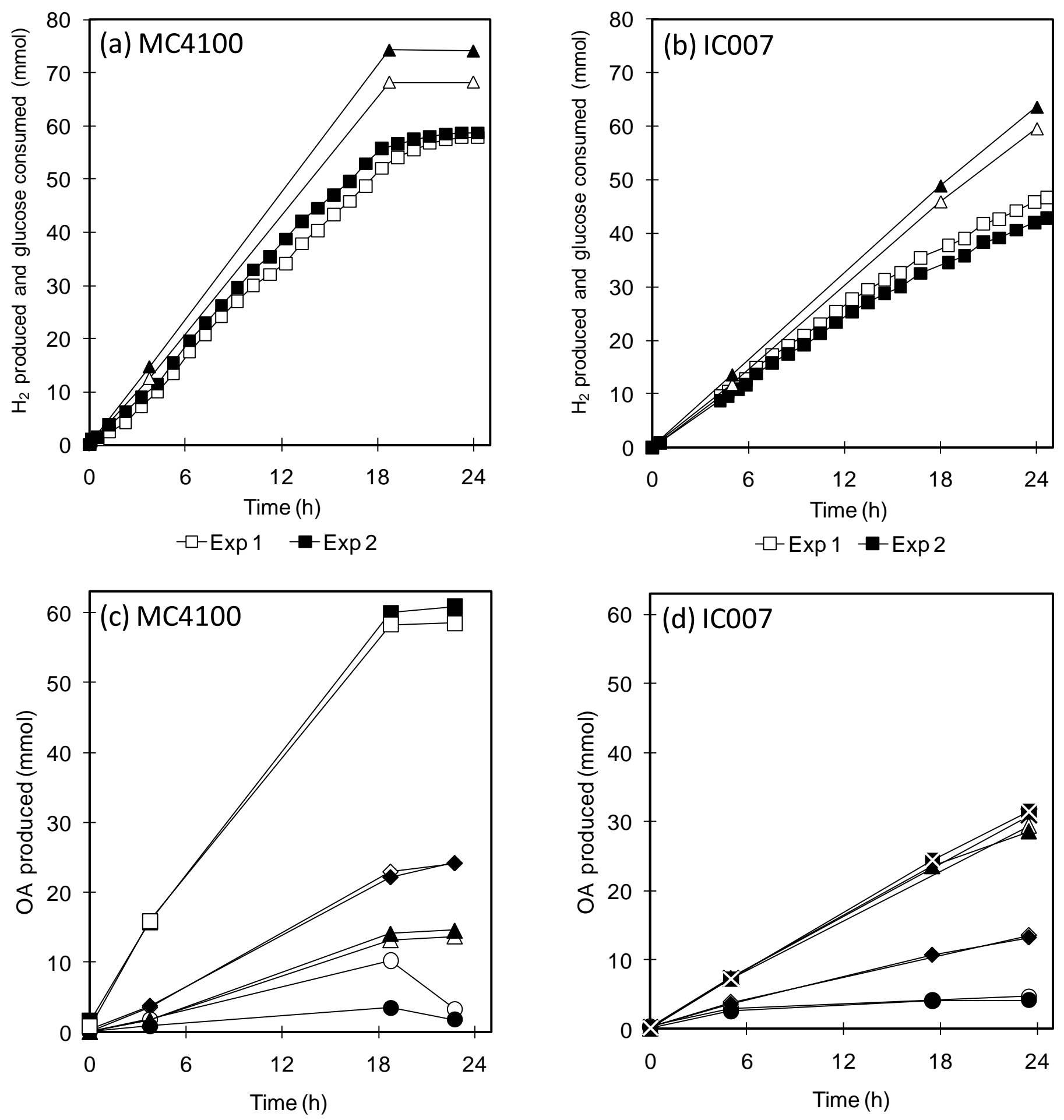

Figure 1. Hydrogen production (a,b) and organic acid production (c,d) from E. coli MC4100 (a,c) and IC007 (b,d). Open and filled symbols represent two independent experiments. Hydrogen production and glucose utilization (a,b) are shown as total mmoles to aid comparison. Masses are shown in mmol: $(\triangle, \mathbf{A})$ Glucose utilization; ( $\square$, $\mathbf{\square})$ Hydrogen production in a and b. Fermentation products in $\mathrm{c}$ and $\mathrm{d}$ are: $(\square, \boldsymbol{\square})$ lactate; $(\diamond, \diamond)$ acetate; $(\mathrm{O}, \boldsymbol{O})$ formate; $(\triangle, \mathbf{\Delta})$ succinate; $(\boldsymbol{X}, \boldsymbol{\otimes})$ pyruvate. 


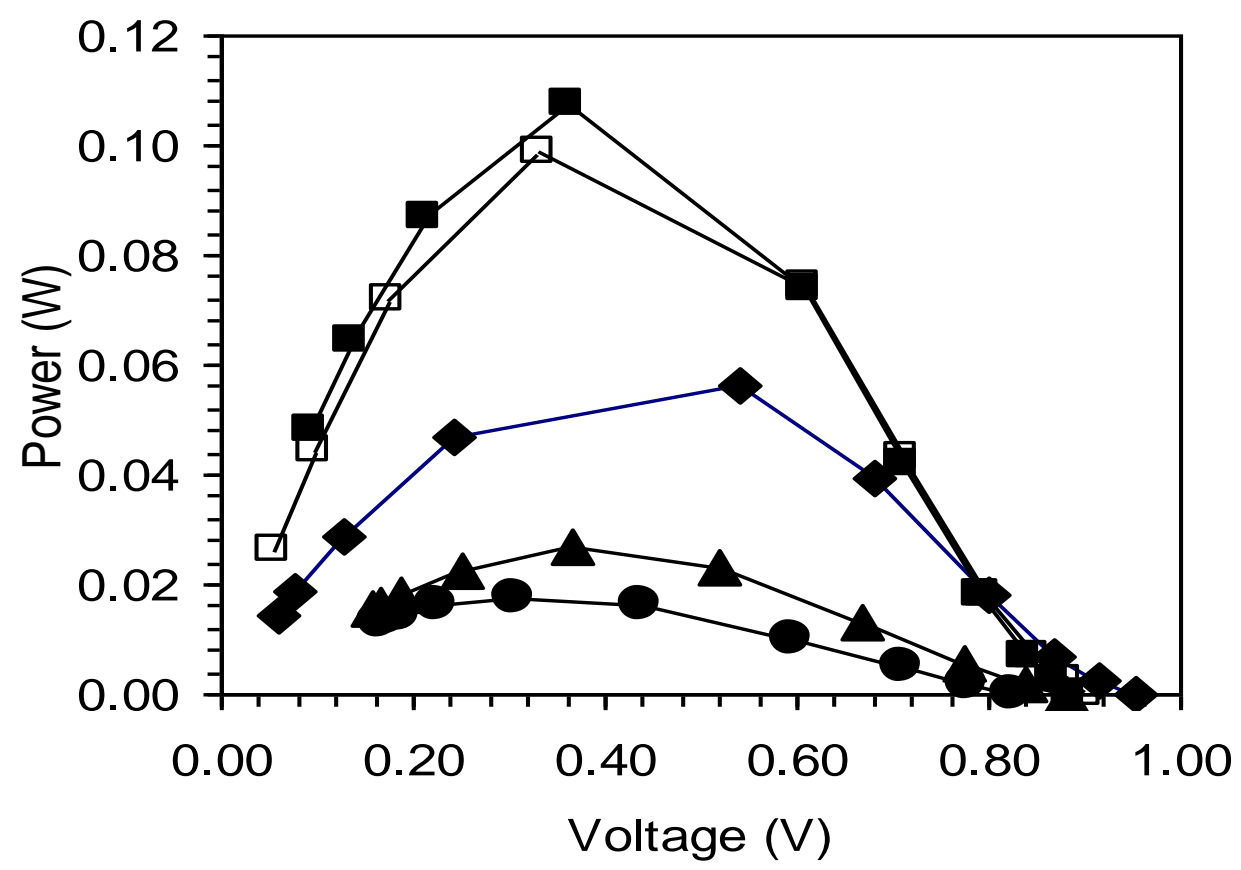

Figure. 2. Power production in a PEM fuel cell using alternative anode catalysts: commercial $\operatorname{Pd}(0)(\square)$ and palladised,

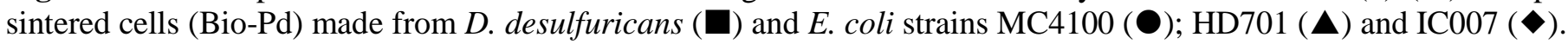

